\title{
Investigating Mentor Teachers' Roles in Mentoring Pre-Service Teachers' Teaching Practicum: A Malaysian Study
}

\author{
Biao Li Phang ${ }^{1}$, Badariah Binti Sani ${ }^{2} \&$ Nur Aizuri Binti Md Azmin ${ }^{2}$ \\ ${ }^{1}$ Institute of Postgraduate Studies and Research, Universiti Tunku Abdul Rahman, Kampar, Malaysia \\ ${ }^{2}$ Faculty of Arts and Social Science, Universiti Tunku Abdul Rahman, Kampar, Malaysia \\ Correspondence: Biao Li Phang, Institute of Postgraduate Studies and Research, Universiti Tunku Abdul Rahman, \\ Kampar, Jalan Universiti, 31900, Malaysia.
}

Received: September 13, 2020

doi: $10.5539 /$ elt.v13n11p1

\author{
Accepted: October 5, 2020 \\ Online Published: October 13, 2020 \\ URL: https://doi.org/10.5539/elt.v13n11p1
}

\begin{abstract}
A teaching practicum is a course of study in which pre-service teachers get to experience actual teaching in real classrooms. Mentor teachers who are assigned to mentor and supervise pre-service teachers have many important roles to play in the practicum experience, yet no extensive research has been conducted on these roles. This study sought to determine the roles played by mentor teachers in pre-service teachers' teaching practicum. Using an explanatory, sequential, mixed-methods research design pertaining to the Malaysian context, we recruited 385 pre-service teachers who had attended teaching practicum and 6 mentor teachers who had previously mentored pre-service teachers. Online questionnaires and telephone interviews were used sequentially. Findings showed that mentor teachers played moderate roles in mentoring pre-service teachers; mentor teachers perceived themselves to play many roles yet regarded certain roles as unnecessary and unimportant. Universities, secondary schools, and the Malaysian Ministry of Education must address the importance of producing quality teachers by intervening as early as pre-service teachers' teaching practicum.
\end{abstract}

Keywords: mentor teacher, pre-service teacher, mentoring roles, teaching practicum

\section{Introduction}

Pre-service teachers attend teaching practicum to bridge the gap between theories and knowledge obtained in lectures and actual classroom teaching (Gan, 2013; Melor et al., 2010). Although teaching practicum offer many opportunities, some pre-service teachers have dreadful experiences in their teaching practicum, and many have since left the profession after obtaining their qualifications and placements in schools (Gan, 2013; Melor et al., 2010; Taghreed \& Mohd, 2017; Tee et al., 2015).

Demand for quality teachers has always been high around the world, including in Malaysia where teachers, regardless of ethnicities, backgrounds, and specializations, must uphold and familiarize themselves with the aspirations listed in the Malaysian National Education Philosophy (Goh \& Blake, 2015; Tee et al., 2015). To meet this demand, more attention should be given to pre-service teachers in teacher education programs. Specifically, more attention should be given to the teaching practicum, as it is an opportunity for pre-service teachers to receive guidance to further master the needed concepts, skills, and tools of the teaching profession before completing their programs (Gan, 2013; Malaysian Qualifications Agency, 2014; Mohd et al., 2014).

\subsection{Research Problems}

This study examined in a general sense the teaching practicum as experienced by pre-service teachers. Regardless of the international context or the Malaysian context, an abundance of research has already been conducted on teaching practicum. A search of the literature indicated that Malaysian researchers have often focused on the challenges and concerns faced by pre-service teachers in teaching practicum (see Goh \& Matthews, 2011; Lokman et al., 2014; Mohd et al., 2014; Melor et al., 2010; Rosilawati, 2013; Shireena et al., 2011; Taghreed \& Mohd, 2017). Findings from these research papers can be summarized into four themes related to the challenges and concerns pre-service teachers frequently face: classroom management, environment, pedagogical, and other. These challenges and concerns affected pre-service teachers professionally and psychosocially throughout their teaching practicum, and when they experienced prolonged and dreadful negativities in their teaching practicum, they were much more likely to quit the profession upon completing their 
teacher education programs (Taghreed \& Mohd, 2017; Tee et al., 2017). If this continues to happen, there is a possibility that Malaysian schools will lack young teachers and thus fail to contribute to or fulfill the country's aspirations. This is because young teachers are needed to bring in their passions and dedications to continue realize the country's aspirations.

Among the challenges and concerns faced by pre-service teachers during their teaching practicum, some Malaysian researchers have highlighted, are mentor teachers who are problematic rather than helpful (see Goh \& Matthews, 2011; Lokman et al., 2014; Melor et al., 2010; Taghreed \& Mohd, 2017). Goh and Matthews (2011) found that mentor teachers were perceived as overly strict figures who placed too many expectations on pre-service teachers, to the extent that meetings initiated by the pre-service teachers were to please the mentor teachers and thereby gain better marks. Lokman et al. (2014) reported that meetings between both sides were initiated only when pre-service teachers needed help after facing a great deal of challenges. Melor et al. (2010) found that mentor teachers did not bother to initiate communications or perform their duties to the pre-service teachers. Similarly, Taghreed and Mohd (2017) found that mentor teachers did not pay any attention to the pre-service teachers and got upset easily whenever meetings were held between the two parties.

Apart from these findings, and unlike research done in the international context, no research in Malaysia has looked further into the roles that mentor teachers play in teaching practicum. Do mentor teachers ever use their positions to address pre-service teachers' concerns and help them cope with the challenges they face in teaching practicum? Are mentor teachers' impacts during the teaching practicum not significant enough to warrant further research? Elected by school principals, mentor teachers are supposed to be friendly and approachable while playing various support roles, including facilitating and supervising pre-service teachers as they conduct lessons throughout the teaching practicum (Goh \& Blake, 2015; Lee, 2014; Mohd et al., 2014; Sami et al., 2013). Hudson, in his many years of conducting studies on mentoring pre-service teachers, stressed that in-service teachers should not merely assume the designation as mentor teachers and be present during the teaching practicum (Crasborn et al., 2011; Hudson, 2010; Izadinia, 2017); rather, they should also play their roles appropriately by demonstrating professionalism and personal attributes that will help develop pre-service teachers into proficient, capable teachers (Hudson, 2010).

Therefore, to enrich the literature on the state of mentoring and the roles that mentor teachers play in the Malaysian context, as well as further enable mentor teachers to understand their roles, this study has the following research objectives: 1) to determine the roles played by mentor teachers in pre-service teachers' teaching practicum and 2) to explore the perceptions of mentor teachers with regard to the roles played in mentoring pre-service teachers during teaching practicum.

\subsection{Literature Review}

The Merriam-Webster dictionary defines role as "a function or part performed especially in a particular operation or process" (Merriam-Webster, n.d.). In pre-service teachers' teaching practicum, mentor teachers' roles, if they are played to a great extent and significant, will have a profound impact on the upbringing of these young, future educators in the teaching profession (Hudson, 2010; Hudson, 2013; Sami et al., 2013). This is certainly true as mentor teachers are often the immediate people pre-service teachers refer to when they need guidance in their teaching practicum (Crasborn et al., 2011). Mentor teachers should make use of these opportunities to develop pre-service teachers (Crasborn et al., 2011; Izadinia, 2017; Lee, 2014).

In the Malaysian context, the Malaysia Education Blueprint explicitly stated that teachers' contributions to the classroom must be effective since their first day of teaching in schools (Ministry of Education, 2013). This logically included pre-service teachers as well. Mentor teachers should thus make use of the teaching practicum opportunity to help mold and shape pre-service teachers to be competent teachers (Hudson, 2010; Hudson, 2013).

To develop professionalism among teachers, the Malaysian Ministry of Education produced a manual for mentor teachers known as the Manual for New Teacher Development Program (Ministry of Education, 2015). This manual outlined the three phases mentor teachers should follow to develop pre-service teachers: the orientation phase, the mentoring phase, and the professional development phase (Ministry of Education, 2015). Each phase comes with specific objectives, specific durations to execute the phases, and the necessary roles mentor teachers need to play to achieve desired outcomes. The following outlines the objectives of each phase:

1. Orientation phase. This phase aims to assist new teachers in adapting to the school's environment, community, and culture so as to help them perform as real teachers in the actual school setting.

2. Mentoring phase. This phase aims to have mentor teachers provide structured, professional guidance and 
support to the new teachers so the new teachers will develop and achieve teaching professionalism based on the six criteria listed in the Ministry's Professionalism Competency.

3. Professional development phase. This phase aims to guide and develop new teachers in terms of increasing their existing knowledge, skills, and values relevant to $21^{\text {st }}$-century teaching.

However, the target teachers that mentor teachers are told to guide are recent graduates, those who have just been assigned to schools and are fresh and new to the profession; the manual does not focus on pre-service teachers. It can, however, be logically argued that the roles stated in the manual can serve as a guide even for mentor teachers who are mentoring pre-service teachers in teaching practicum.

Although none of the literature in the Malaysian context explicitly discusses the roles of mentor teachers in teaching practicum, amongst the literature that revealed mentor teachers who were perceived to be problematic by the pre-service teachers (see Goh \& Matthews, 2011; Lokman et al., 2014; Melor et al., 2010; Taghreed \& Mohd, 2017), there were at least two studies (Muhammad, 2013; Mohd et al., 2014) in which pre-service teachers mentioned that their mentor teachers were helpful. Muhammad (2013) only mentioned that the mentor teachers were generally helpful. However, Mohd et al. (2014) included further explanations of the mentor teachers' helpfulness; for example, the mentor teachers provided various useful suggestions and guidance to the pre-service teachers even as they offered constructive criticisms. By comparing these findings to the rich literature on mentoring in the international context, these mentor teachers appear to have provided feedback to help pre-service teachers in improving their performance (Hudson, 2010; Yirci et al., 2015) and guidance to help pre-service teachers persist through their teaching practicum (Crasborn et al., 2011; Hudson, 2010; Yirci et al., 2015).

However, the findings provided by Muhammad (2013) and Mohd et al. (2014) were too general, and they were the only literature from the Malaysian context that was accessible and credible. Hudson (2010), in his studies on mentor teachers over many years, developed a model outlining the roles mentor teachers should play; Yirci et al. (2015) provided two different classifications of roles; and other scholars discussed roles ranging from classroom management to institutional adjustment that mentor teachers should play in teaching practicum (see Crasborn et al., 2011; Duah, 2010; Galamay-Cachola et al., 2018; Izadinia, 2017). Although this literature provides many more examples of the roles mentor teachers should play compared to the findings provided in the Malaysian context, a grey area involving mentor teachers' roles when mentoring pre-service teachers still exists in the Malaysian context, thus requiring further investigation.

Roles played by mentor teachers have been discussed extensively by researchers such as Hudson (2010) and Yirci et al. (2015). Yirci et al. (2015) sees mentor teachers' roles as providing professional and psychosocial support to pre-service teachers; they define professional support as enhancing pre-service teachers' professionalism in teaching and psychosocial support as boosting pre-service teachers' self-efficacy. They assert that mentor teachers should possess a reservoir of pedagogical knowledge and experience that they can share to help build pre-service teachers' professionalism. They also state that mentor teachers should build close relationships with pre-service teachers, initiate communication with them, support them through appropriate counselling, and confirm their identity as teachers to help in fostering their well-being and confidence throughout the teaching practicum.

Hudson developed a model known as the Five Factor Mentoring Model (Hudson, 2010; Hudson, 2013). Through rigorous statistical testing, compiling, and categorizing the list of roles that he identified in his various research studies, Hudson concluded that the five factors mentor teachers need to be aware of are 1) personal attributes, 2) system requirements, 3) pedagogical knowledge, 4) modelling, and 5) feedback. When mentor teachers fulfill their roles according to these factors, pre-service teachers experience significant development as teachers in the profession (Hudson, 2010; Hudson, 2013). Hudson (2010) described the five factors as follows:

1. Personal attributes. Mentor teachers are required to play interpersonal-related roles when mentoring pre-service teachers in a comfortable manner such as being attentive and supportive listeners and confidence builders.

2. System requirements. Mentor teachers are required to have a reservoir of knowledge related to the education system.

3. Pedagogical knowledge. Mentor teachers are also required to have a reservoir of pedagogical knowledge where they share effective, useful pedagogical-related practices with the pre-service teachers.

4. Modelling. Mentor teachers have to demonstrate and model good attitudes, behaviours, and values as teachers in and out of the classroom. 
5. Feedback. Mentor teachers have to constantly provide feedback, both written and oral, with the purpose of improving the pre-service teachers as teachers.

While the mentoring roles provided by the Manual for New Teacher Development Program and Yirci et al. (2015) may show some similarity to the roles outlined by Hudson's Five Factor Mentoring Model, the extent of similarity among these roles is not the focus of this study because neither the manual nor Yirci et al. (2015) mentioned Hudson's model; it would therefore be inappropriate to conflate them as a single subject to explore in this study. As such, we used Hudson's Five Factor Mentoring Model as the theoretical framework to study mentor teachers' roles in teaching practicum because this model informed the various roles based on the five factors needed when mentoring pre-service teachers.

\subsection{Theoretical Framework}

In describing his Five Factor Mentoring Model, Hudson contended that the compilation of roles categorized into the corresponding factors has the possibility of strengthening the mentoring process and providing a meaningful teaching practicum experience to the pre-service teachers, ultimately leading to the development of pre-service teachers as capable teachers by the end of the teaching practicum (Hudson, 2010; Hudson, 2013). He further emphasizes that each factor with its corresponding roles has implications that are significant to pre-service teachers. When personal attributes are involved, the relationship between pre-service teachers and mentor teachers can be strengthened in a friendly manner, allowing the other roles to be comfortably played by the mentor teacher; system requirements help pre-service teachers to have a clearer understanding of how the education system works; pedagogical knowledge enables pre-service teachers to carry out lessons effectively; modelling helps pre-service teachers to develop positive and professional attitudes as teachers; and feedback contributes to further improving pre-service teachers' performance as teachers working in schools (Hudson, 2010; Hudson, 2013).

Acknowledging the importance of mentor teachers' roles in the upbringing of pre-service teachers during teaching practicum, recent research by Duah (2010) from England and Galamay-Cachola et al. (2018) from the Philippines employed questionnaires and conducted surveys of pre-service teachers using the Five Factor Mentoring Model. Duah (2010) focused on mathematics and science teachers' responses while Galamay-Cachola et al. (2018) disregarded the subject specialization of pre-service teachers in a university. Duah (2010) found that mentor teachers played a great extent of the roles from the feedback factor, while Galamay-Cachola et al. (2018) found that mentor teachers played a great extent of the roles from the personal attributes factor. Regardless, both papers highlighted the need for mentor teachers to receive proper and intensive training to ensure that they fulfill roles from the other factors to an equal extent. Their research, however, was limited to pre-service teachers either from a university or subject-specific teacher education programs.

The significance of using Hudson's Five Factor Mentoring Model is thus clear: the roles played by mentor teachers can be identified, and the extent of these roles can be determined. Findings from this present study conducted helped provided a comprehensive, descriptive picture on the state of mentoring, further enabling proper suggestions to be made to help overcome the challenges faced by pre-service teachers and enriching the literature of mentoring in the Malaysian context.

\section{Method}

\subsection{Explanatory, Sequential, Mixed-Methods Design}

We used an explanatory, sequential, mixed-methods research design to conduct the study because such a design provides richer data to describe a phenomenon than a mere quantitative or qualitative research design can (Creswell, 2014; Md Shidur, 2017). We first used a quantitative inquiry and then a qualitative inquiry (Creswell, 2014). To provide a comprehensive overview on the state of mentoring in Malaysia, we recruited 385 pre-service teachers to determine their perceptions on the roles mentor teachers had played in their teaching practicum; we then recruited six mentor teachers to explore their perceptions of the roles they had played when they were mentoring pre-service teachers. The mentor teachers' responses were further analysed to inform the findings obtained from the pre-service teachers' responses.

\subsection{Description of Research Participants}

The pre-service teachers were recruited from various universities in Malaysia, both public and private. They were recruited based on the Malaysian Qualifications Agency's (MQA) list of universities that offered teacher education programs. The pre-service teachers were recruited to achieve the quantitative inquiry of our research design, as we aimed to generalize their perceptions about the roles that their mentor teachers played in their teaching practicum to the entire pre-service teacher population in Malaysia. The nature of quantitative inquiry in 
research often involves generalization of findings to the population being studied (Creswell, 2014).

Mentor teachers were recruited from various schools in Malaysia. These mentor teachers were in-service teachers who had previously mentored teachers at least once. They were recruited to achieve the qualitative inquiry in the research design, where their perceptions of the roles played were explored through interviews. Their responses were further investigated to explain and discuss the findings obtained in the quantitative inquiry on pre-service teachers.

\subsection{Sampling Procedures}

The pre-service teachers were recruited through the use of a multistage sampling method. Such a method involves more than one type of sampling to recruit research participants who best meet the research objectives (Sedgwick, 2015). Thus, we purposely selected pre-service teachers who had attended their teaching practicum. Only those who had attended their teaching practicum were selected as they already had an experience with their respective mentor teachers, and it was assumed that they knew the roles that the mentor teachers had played in the teaching practicum. The research instrument was randomly distributed to these pre-service teachers to eliminate bias and simultaneously enable generalization to the entire pre-service teacher population.

Mentor teachers were recruited through the snowball sampling method. Once a mentor teacher was successfully contacted, they were asked to provide contacts for other teachers who had previously been assigned as pre-service teachers' mentors. This method was used until six mentor teachers were successfully interviewed.

\subsubsection{Determining the Size}

We used Cochran's sample size formula to determine the needed size to conduct this study when the actual size of the population being investigated was not available (Doshmanziari \& Mostafavi, 2017; Masoumparast, 2016). This formula was used because it was not possible to determine the actual number of pre-service teachers who had attended their teaching practicum in a particular semester. It was also used because there was a possibility of pre-service teachers altering the course structure in the program studied, rendering the exact figure of pre-service teachers who had attended their teaching practicum unavailable. At a $95 \%$ confidence level, the sample size needed to provide generalization to the population was 385 pre-service teachers. The formula to determine the sample size was as followed:

$$
n_{0}=Z^{2} p q / e^{2}
$$

\subsection{Research Instruments}

A questionnaire was adapted from Galamay-Cachola et al. (2018) with permission and was piloted on 30 pre-service teachers to ensure its validity and reliability. The questionnaire used a 4-point Likert scale and had 24 items related to the roles described in the Five Factor Mentoring Model. The Cronbach's alpha was at .96, which was proven to be very reliable. The questionnaire was presented using Google Forms and distributed to the pre-service teachers after obtaining consent from their universities. 10 semi-structured interview questions were prepared and piloted to ensure the questions were properly structured and clear and the needed data would be obtained. The interview questions were used during telephone interviews with the mentor teachers after their consent was obtained.

\subsection{Data Analysis}

Data obtained through the online questionnaire was analysed using descriptive statistics, particularly the mean, which helped determine the extent of roles played. The extent of roles based on the means obtained was interpreted using Galamay-Cachola et al.'s interpretation (2018): no mentoring (1.00-1.49), little extent of mentoring (1.50-2.49), moderate extent of mentoring (2.50-3.49), and great extent of mentoring (3.50-4.00). Interview responses obtained were recorded, transcribed, and coded to generate necessary themes in explaining mentor teachers' perceptions of their roles played.

\section{Discussion}

The data collection process took ten weeks, from February 2020 to April 2020, and 385 pre-service teachers' responses to the online questionnaire were obtained. Using mean as a form of descriptive statistics, Table 1 presents the extent of roles played by mentor teachers, which are categorized into their corresponding factors in the Five Factor Mentoring Model. 
Table 1. Extent of roles played by mentor teachers

\begin{tabular}{lll}
\hline Factor & Mean & Interpretation \\
\hline Personal attributes & 3.15 & Moderate \\
System requirements & 3.01 & Moderate \\
Pedagogical knowledge & 3.12 & Moderate \\
Modelling & 3.10 & Moderate \\
Feedback & 3.20 & Moderate
\end{tabular}

Using Galamay-Cachola et al.'s (2018) interpretation, the overall means for each factor were astounding, as all of the means were interpreted as a "moderate extent of mentoring," which meant that the means were between 2.50 and 3.49. Despite the same interpretation, the factors can be ranked accordingly, with the feedback factor having the highest mean (3.20) and the system requirements factor having the lowest mean (3.01), which barely passed the 3.0 mean threshold. The remaining factors had means that were not that distinct from each other, as they all lied around 3.10.

Because feedback had the highest mean amongst the other four factors, it can be inferred that mentor teachers did emphasize providing feedback to pre-service teachers. Feedback was often perceived to be the most important factor as it aimed to help the pre-service teachers to improve themselves in their teaching (Hudson, 2010; Hudson, 2013). Mentor teachers were supposed to provide feedback with every observation conducted on pre-service teachers (Gan, 2013; Mohd et al., 2014). However, it can be inferred that if the mentor teachers only provided feedback after conducting observations, the feedback would not be sufficient and would defeat the purpose of improving the pre-service teachers' performance (Hudson, 2010; Hudson, 2013). Such a situation could explain why pre-service teachers only reported a moderate extent of feedback.

Second to the feedback factor was personal attributes, which had a mean of 3.15. The relationship between a mentor teacher and pre-service teacher must be positive for mentoring to occur (Hudson, 2013; Yirci et al., 2015), but when a moderate extent of the personal attributes factor is shown, the positive relationship between mentor teacher and pre-service teacher might not develop. Literature focusing on pre-service teachers has highlighted that some mentor teachers are overly strict, set high expectations, pay insufficient attention to the pre-service teachers' concerns, and get upset easily (Goh \& Matthews, 2011; Lokman et al., 2014; Taghreed \& Mohd, 2017), which might explain why the relationship between mentor teachers and pre-service teachers was only at a moderate extent. Mentor teachers should be reminded that having such a title does not show their superiority over pre-service teachers but rather a mandate to be a friend and counsellor to the pre-service teachers, further developing trust between both sides that boosts the quality of the teaching practicum (Hudson, 2010; Hudson, 2013; Sami et al., 2013; Yirci et al., 2015).

The lowest mean recorded was the system requirements factor (3.01). Hudson (2010; 2013) emphasized that explaining system requirements such as the curriculum, syllabus, and policies to the pre-service teachers is important in helping pre-service teachers understand how the education system works. Goh and Blake (2015) emphasized that mentor teachers should always inform pre-service teachers about the Malaysian education system as the system often changes, especially in terms of the curriculum and policies. They also stressed that pre-service teachers must keep themselves updated on the education system to ensure their performance is in line with the education aspirations set by the Malaysian Ministry of Education. However, with the lowest mean recorded in this study, it can be inferred that mentor teachers did not provide sufficient knowledge to the pre-service teachers on system requirements in their teaching practicum.

Furthermore, while the interpretation of these means shows that mentor teachers played their roles in mentoring pre-service teachers during the teaching practicum, this does not mean that the roles played were sufficient. The overall state of mentoring in the Malaysian context does not appear to be positive; moreover, the situation appears to have worsened, as the means obtained by Galamay-Cachola et al. (2018) were significantly different from our findings. Table 2 presents the comparison of means between the present study and Galamay-Cachola et al.'s (2018). Evidently, the highest mean from Galamay-Cachola et al.'s (2018) findings was 3.66 and the lowest was 3.31, both of which were greater than the highest mean (3.20) obtained in our study. A common finding between the two sides was that the system requirements factor had the lowest mean. Regardless, unlike the present findings, in which all the means were interpreted as a moderate extent of roles played in mentoring, the means for personal attributes, modelling, and feedback factors were all interpreted as a great extent of roles played in Galamay-Cachola et al.'s (2018) research. 
Table 2. Comparison of means of two studies

\begin{tabular}{lll}
\hline Present research (mean) & Factors & Galamay-Cachola et al. (mean) \\
\hline 3.15 & Personal attributes & 3.66 \\
3.01 & System requirements & 3.31 \\
3.12 & Pedagogical knowledge & 3.46 \\
3.10 & Modelling & 3.55 \\
3.20 & Feedback & 3.61
\end{tabular}

Each factor has roles that mentor teachers have to play, and it is the mentor teachers' responsibility to play these roles because they have a significant impact on the pre-service teachers in their teaching practicum (Galamay-Cachola et al., 2018; Hudson, 2013). The development of pre-service teachers in teaching practicum will only be meaningful and significant if mentor teachers play their roles to a great extent (Galamay-Cachola et al., 2018). Mere presence of the mentor teacher figure in the teaching practicum, and providing mentoring for the sake of mentoring, are simply insufficient (Crasborn et al., 2011; Galamay-Cachola et al., 2018; Hudson, 2010; Hudson, 2013; Izadinia, 2017). Literature on pre-service teachers, as discussed earlier, negatively portrays mentor teachers; Taghreed and Mohd (2017), for example, reported how pre-service teachers dealt with a great amount of challenges, yet mentor teachers played only minimum roles to help them. When combined with the findings obtained in this study, it appears that mentor teachers in general and across Malaysia have not played their roles sufficiently. They might not be aware of the importance of the roles they should play, or they may simply not be mentoring pre-service teachers.

Interview responses were obtained from six mentor teachers, and these responses were transcribed and analysed through coding and thematic analysis. The mentor teachers interviewed stated that they had taught in schools for at least a decade; two of the mentor teachers had almost 40 years of teaching experience, although none of them had more than 10 years of mentoring experience with pre-service teachers. From the analyses conducted, a total of five themes were identified.

\subsection{Mentor Teachers Perceived Themselves as Holding Multiple Identities}

Other than perceiving themselves as mentors to the pre-service teachers in teaching practicum, the mentor teachers interviewed perceived themselves to have a good relationship with the pre-service teachers and had assumed other identities such as an advisor, counsellor, facilitator, guide, and motivator, as shown by the following quotation from a mentor teacher:

I believe as a mentor, my role is to be a guide, counsellor, and advisor as well because, you know, the trainees need some guidance. They also feel stress, so I need to be a counsellor as well. (Hall, lines 23-27)

The quotation shows that the mentor teacher perceived herself to hold at least three identities. Roles mentioned, such as being a counsellor and motivator along with the claims of having a good relationship with the pre-service teachers, must be played by the mentor teachers; as Lokman et al. (2014) and Yirci et al. (2015) claimed, a positive relationship between mentor teachers and pre-service teachers extends the possibility of positive development through providing various psychosocial supports to the pre-service teachers.

\subsection{Mentor Teachers Perceived that Meetings Should Be Held on a Variable Basis}

Mentor teachers claimed that they held meetings with the pre-service teachers. However, these meetings were held on an inconsistent basis. Some mentor teachers were unable to provide how often they met with the pre-service teachers.

Depending on the situation and if the mentee meets me every day, it will be a problem." (Lane, lines 42-45)

Mentor teachers believed that they had met the pre-service teachers when the pre-service teachers needed help. Another mentor teacher provided a specific time frame as to when she met the pre-service teacher.

Actually, I meet my mentee [pre-service teacher] once in two weeks but also when necessary because they might have any problems or dilemma, they can see me anytime. (Kim, lines 49-52)

Such responses were similar to Lokman et al.'s (2014) findings: the pre-service teachers claimed that meetings held between the two parties happened because the pre-service teachers needed help from their mentor teachers. If pre-service teachers do not have any problems, it becomes questionable if there is any meeting that occurs 
between both sides. Moreover, the negative portrayal of mentor teachers in terms of their attitudes - as highlighted by Goh and Matthews (2011), Melor et al. (2010), and Taghreed and Mohd (2017)—might also result in few meetings between pre-service teachers and mentor teachers. Goh and Matthews (2011), for example, stated that pre-service teachers were doubtful about meeting their mentor teachers as the mentors were overly strict. The mentor teachers' responses in their study certainly confirmed such a situation was true in the pre-service teachers' teaching practicum.

Further, Yirci et al. (2015) mentioned that meetings must be held on a regular basis by the mentor teachers as they need to provide professional and psychosocial support to the pre-service teachers, which ultimately boosts their performance and self-efficacy. But when meetings are inconsistent, the support given to the pre-service teachers may be at a minimum, which would explain the occurrence of a moderate extent of mentoring in teaching practicum.

\subsection{Mentor Teachers Had Vague Responses on System Requirements}

Mentor teachers were seemingly unsure of the roles related to system requirements even with explanations and clarifications provided. One mentor teacher claimed to have shared whatever was deemed necessary but did not provide examples.

Yes. I just tell them whatever I'm supposed to tell and if it is relevant to the thing, I will just explain to them, whatever related to the school. I will explain to them whatsoever, whatever necessary. (Tom, lines 154-156)

Clearly, his responses were vague as the word "whatever" was repeatedly used with no concrete examples, suggesting that he might have no knowledge about the roles related to system requirements. While Hudson (2010) stated that orientation was necessary to help pre-service teachers understand the school's system, environment, and culture, a mentor teacher expressed that it was not necessary.

In my humble opinion, I think orientation is not necessary because I think they already have it at [the] university level, right? I believe they came in with ample information so they don't need another session of orientation." (Mary, lines 95-97)

Clearly, she believed that it was the university's responsibility to provide orientation to the pre-service teachers. It should be pointed out that even if the university had pointed orientation, mentor teachers would still need to perform such a role because logically, mentor teachers are the ones that are most familiar with how the school where they work functions. By relating mentor teachers' responses, which were vague and claimed that orientation was unnecessary, to our quantitative findings, which show that pre-service teachers perceived mentor teachers' roles on system requirements as only at a moderate extent (3.01), we can infer that mentor teachers may not have shared sufficient knowledge of system requirements with the pre-service teachers. As such, pre-service teachers were reportedly suffering from confusion about how the education system works (Goh \& Matthews, 2011; Izadinia, 2017; Mohd et al., 2014; Taghreed \& Mohd, 2017).

\subsection{Mentor Teachers Claimed to Share Various Practical Pedagogical Knowledge}

Mentor teachers claimed to have shared a wide range of practical pedagogical knowledge with the pre-service teachers. Table 3 shows the list of pedagogical knowledge shared by the mentor teachers interviewed.

Table 3. Pedagogical knowledge shared by mentor teachers

\begin{tabular}{ll}
\hline Mentor teachers & \multicolumn{2}{l}{ Pedagogical knowledge shared } \\
\hline Lane & - Students' discipline \\
& - Classroom management \\
Mary & - Lesson planning \\
& - Teaching strategies \\
Hall & - Classroom management \\
Kim & - Teaching methods \\
& - Teaching methods \\
Ellis & - Teacher-student interaction \\
& - Tesson planning \\
Tom & - Teaching materials \\
& - Teaching methods \\
\hline
\end{tabular}


Unlike Hall, who only mentioned one example of pedagogical knowledge shared, the other mentor teachers shared at least two examples related to pedagogical knowledge. Regardless, the examples of pedagogical knowledge shared were similar, relating to such topics as classroom management, teaching methods, and teaching materials. The examples given reflect the examples of pedagogical knowledge mentor teachers should possess that are discussed in the international literature on mentor teachers' roles (Gan, 2013; Goh \& Matthews, 2011). Mentor teachers need to have a reservoir of pedagogical knowledge (Hudson, 2010; Hudson, 2013; Yirci et al., 2015), and from these mentor teachers' interview responses, they seem to have such a reservoir.

\subsection{Mentor Teachers Objected to Being Observed by Pre-Service Teachers}

Analysis of the mentor teachers' responses revealed that they claimed to have shown many professional practices to the pre-service teachers such as good values, positive interactions, and proper attire. However, all six mentor teachers rejected the role of allowing pre-service teachers to observe them in teaching students, with the justification that it would make them feel "uncomfortable."

No. It's not comfortable, right? It's not comfortable. I'm always scared of observations because I have been teaching for almost 10 years and I don't know what my mentee [pre-service teacher] has in her mind." (Mary, lines 71-72)

Actually, no. I think not all teachers will allow the trainees [pre-service teachers] to observe them while they teach because they don't like that. They have been through observations and they don't really like that, what's more with the older teachers. (Lane, lines 179-181)

Despite the justifications that the mentor teachers provided, refusing to allow pre-service teachers to observe them while they teach contradicts with Hudson's (2010) assertion that mentor teachers are needed to demonstrate proper teachings so as to enable pre-service teachers to model these teachings and execute them in classrooms. Gan (2013) and Izadinia (2017) also mentioned that mentor teachers should demonstrate and translate their pedagogical knowledge in classrooms, which will help pre-service teachers bridge their understanding to real classroom application. If the mentor teachers are not confident in bringing their pedagogical knowledge into real classroom practice, pre-service teachers may not be able to bridge the gap between pedagogical knowledge and real classroom practice.

It is possible that these mentor teachers did not possess the confidence to present their teachings to the pre-service teachers. If true, it would be ironic; as Muhammad (2013), Yirci et al. (2015), and Hudson (2010) claimed, mentor teachers are supposed to be the ones instilling confidence in pre-service teachers. Mentor teachers must be confident in their capabilities as teachers, as this will help facilitate and develop the pre-service teachers to be more confident with their teachings (Hudson, 2010; Hudson, 2013; Izadinia, 2017; Muhammad, 2013).

The five themes reported and discussed show that mentor teachers claim to have played their roles. However, it is doubtful that the relationship between both sides is always positive and that mentor teachers always play their roles because many admitted to having meetings on an inconsistent basis. If the pre-service teachers had not requested help from the mentor teachers, there is a possibility that no mentoring would have occurred. Furthermore, not allowing pre-service teachers to observe them and not providing orientation further proves that mentor teachers did not have enough understanding about their roles. The moderate extent of mentoring identified in the data obtained from the online questionnaire is thus explainable; inconsistent meetings might have contributed to little or no mentoring, meaning that mentor teachers only ever played their roles a few times.

Clearly, mentor teachers played their roles but only to a moderate extent. This is not sufficient because good mentoring and supervision involves a great extent of mentoring to ensure pre-service teachers develop professionally and meaningfully (Galamay-Cachola et al., 2018; Hudson, 2010; Hudson, 2013).

\section{Conclusion}

Challenges in teaching practicum remain in abundance. Mentor teachers who are assigned to mentor and supervise pre-service teachers have roles that they should play to help pre-service teachers overcome these challenges while also developing pre-service teachers into better educators. This study has found that mentor teachers' roles are only played to a moderate extent; some roles are even deemed unnecessary by the mentor teachers, which is insufficient to help in the development of pre-service teachers. Evidently, mentor teachers need to have a better understanding of the roles they should play. The Malaysian Ministry of Education or universities, with the help of these findings, may create guidelines or manuals to help mentor teachers be aware of their roles when they are assigned to mentor pre-service teachers. Mentor teachers with the findings available in this paper must understand and realize that their roles are crucial in the upbringing of the pre-service teachers 
as they will be the future educators who continue to achieve the country's aspirations and implement the education system in schools.

As this research was conducted amidst the COVID-19 pandemic, the Ministry of Health (2020) in Malaysia issued statements to have universities and schools close down temporarily, and movements of people were greatly restricted for safety purposes. This situation affected data collection because there was a possibility that research participants would reject, ignore, or miss their interviews or the questionnaire that was distributed (Crano et al., 2015). Future research may include distributing the survey to mentor teachers as well, which would help in comparing and contrasting the responses of the roles played to determine the extent of truthfulness. Pre-service teachers from the Institutes of Teacher Education should be included as well to provide findings that are generalizable to the entire pre-service teacher population in Malaysia.

\section{Acknowledgments}

This research did not receive any grant from any funding agency in the public, commercial, or not-for-profit sectors. All authors made equal and significant contributions to the study. The entire research was conducted solely as a postgraduate study in the said institution.

\section{References}

Crano, W. D., Brewer, M. B., \& Lac, A. (2015). Principles and methods of social research (3rd ed.). Routledge Taylor \& Francis Group. https://doi.org/10.4324/9781315768311

Crasborn, F., Hennissen, P., Brouwer, N., Korthagen, F., \& Bergen, T. (2011). Exploring a two-dimensional model of mentor teacher roles in mentoring dialogues. Teaching and Teacher Education, 27(2), 320-331. https://doi.org/10.1016/j.tate.2010.08.014

Creswell, J. W. (2014). Research design: qualitative, quantitative, and mixed methods approaches (4th ed.). SAGE Publications.

Doshmanziari, E., \& Mostafavi, A. (2017). Barriers to use of educational technology in the learning process of primary school students in district 13 in Tehran. International Education Studies, 10(2), 44-53. https://doi.org/10.5539/ies.v10n2p44

Duah, F. K. (2010). Benchmarking mentoring practices for effective teaching of mathematics and science. Paper presented at the BSRLM Proceedings, Newcastle University. Retrieved from http://eprints.chi.ac.uk/id/eprint/3798/1/BSRLM-IP-30-3-06.pdf

Galamay-Cachola, S., Aduca, C. M., \& Calauagan, F. C. (2018). Mentoring experiences, issues, and concerns in the student teaching program: Towards a proposed mentoring program in teacher education. IAFOR Journal of Education, 6(3), 7-24. https://doi.org/10.22492/ije.6.3.01

Gan, Z. (2013). Learning to teach English language in the practicum: What challenges do non-native ESL student teachers face? Australian Journal of Teacher Education, 38(3), 92-108. https://doi.org/10.14221/ajte.2013v38n3.3

Goh, P. S. C., \& Blake, D. (2015). Teacher preparation in Malaysia: Needed changes. Teaching in Higher Education, 20(5), 469-480. https://doi.org/10.1080/13562517.2015.1020780

Goh, P. S., \& Matthews, B. (2011). Listening to the concerns of student teachers in Malaysia during teaching practice. Australian Journal of Teacher Education, 36(3), 92-103. https://doi.org/10.14221/ajte.2011v36n3.2

Hudson, P. (2010). Mentors report on their own mentoring practices. Australian Journal of Teacher Education, 35(7), 30-42. https://doi.org/10.14221/ajte.2010v35n7.3

Hudson, P. (2013). Developing and sustaining successful mentoring relationships. Journal of Relationships Research, 4(1), 1-10. https://doi.org/10.1017/jrr.2013.1

Izadinia, M. (2017). From swan to ugly duckling? Mentoring dynamics and preservice teachers' readiness to teach. Australian Journal of Teacher Education, 42(7), 66-83. https://doi.org/10.14221/ajte.2017v42n7.5

Lee, N. M. S. (2014). Mentoring and developing pedagogical content knowledge in beginning teachers. Procedia Social and Behavioral Sciences, 123, 53-62. https://doi.org/10.1016/j.sbspro.2014.01.1397

Lokman, M. T., Mohd, N. H. M., Roslee, A., Khadijah, D., Bambang, S., \& Suhana, Y. (2014). Exploring the induction program for novice teachers. Life Science Journal, 11(8), 394-406. http://doi.org/10.7537/marslsj110814.52 
Malaysian Qualifications Agency. (2014). Education programme standards. Retrieved from https://www.mqa.gov.my/

Masoumparast, S. (2016). The role of teachers' emotional intelligence and self-efficacy in decreasing students' separation anxiety disorder. International Education Studies, 9(4), 185-194. http://doi.org/10.5539/ies.v9n4p185

Md Shidur, R. (2017). The advantages and disadvantages of using qualitative and quantitative approaches and methods in language "testing and assessment" research: A literature review. Journal of Education and Learning, 6(1), 102-112. http://doi.org/10.5539/jel.v6n1p102

Melor, M. Y., Harwati, H., Noriah, M. I., \& Zamir, M. (2010). Understanding TESL pre-service teachers' teaching experiences and challenges via post-practicum reflection forms. Procedia Social and Behavioral Sciences, 9, 722-728. https://doi.org/10.1016/j.sbspro.2010.12.224

Merriam-Webster. (n.d.). Merriam-Webster.com dictionary. Retrieved from https://www.merriam-webster.com/

Ministry of Education Malaysia. (2013). Malaysia education blueprint 2013-2025 (Preschool to post-secondary education)

Retrieved

from https://www.moe.gov.my/menumedia/media-cetak/penerbitan/dasar/1207-malaysia-education-blueprint-201 3-2025/file

Ministry of Education Malaysia. (2015). Manual for new teacher development program. Retrieved from https://www.moe.gov.my/muat-turun/penerbitan-dan-jurnal/terbitan/buku-panduan-1/1603-panduan-pelaksa naan-program-pembangunan-guru-baharu-ppgb-2015/file

Ministry of Health Malaysia. (2020). Updates on the coronavirus disease 2019 (COVID-19) situation in Malaysia. $\quad$ [Press release]. $\quad$ Retrieved from https://www.moh.gov.my/moh/modules_resources/database_stores/96/337_1380.pdf

Mohd, S. A., Abdul, J. O., \& Abdul, F. A. K. (2014). Issues and concerns faced by undergraduate language student teachers during teaching practicum experiences. The Malaysian Online Journal of Educational Sciences, 2(3), 22-30. Retrieved from https://mojes.um.edu.my/article/view/12837/8231

Rosilawati, S. (2013). Pre-service teachers' classroom management in secondary school: Managing for success in teaching and learning. Procedia Social and Behavioral Sciences, 90, 670-676. https://doi.org/10.1016/j.sbspro.2013.07.139

Sami, A. R. A.-D., Mustafa, A. A., \& Mohd, R. A. M. (2013). Mentoring and perceived stress level among private medical students: A Malaysian perspective. Procedia Social and Behavioral Sciences, 93, 276-280. https://doi.org/10.1016/j.sbspro.2013.09.189

Shireena, B. A. R., Nabilah, A., \& Radzuwan, A. R. (2011). Trainee teachers' readiness towards teaching practice: The case of Malaysia (Paper presented at the Joint Conference UPI-UiTM 2011, Indonesia). Retrieved from https://www.researchgate.net/profile/Nabilah_Abdullah3/publication/266178442_Trainee_Teachers'_Readin ess_Towards_Teaching_Practice_The_Case_of_Malaysia/links/5739bc7008aea45ee83f68f8.pdf

Taghreed, E. M., \& Mohd, R. M. S. (2017). Complexities and tensions ESL Malaysian student teachers face during their field practice. The English Teacher, 46(1), 1-16. Retrieved from https://journals.melta.org.my/index.php/tet/article/view/388/274

Tee, Y. Q., Zarina, R., Zainuddin, I., See, J., Ngu, K. S., Sunitha, M., \& Nabeel, A. (2015). Teachers' background factors and its relation to motivation. Malaysian Online Journal of Educational Management, 3(2), 1-17. Retrieved from https://mojem.um.edu.my/article/view/6086/3797

Yirci, R., Karakose, T., Uygun, H., \& Ozdemir, T. Y. (2016). Turkish adaptation of the mentorship effectiveness scale: A validity and reliability study. Eurasia Journal of Mathematics, Science \& Technology Education, 12(4), 821-832. https://doi.org/10.12973/eurasia.2016.1440a

\section{Copyrights}

Copyright for this article is retained by the author(s), with first publication rights granted to the journal.

This is an open-access article distributed under the terms and conditions of the Creative Commons Attribution license (http://creativecommons.org/licenses/by/4.0/). 